\title{
EL DERECHO A LA TUTELA JURISDICCIONAL EFECTIVA DESDE LA PERSPECTIVA DE LOS DERECHOS FUNDAMENTALES*
}

\author{
Carlos Alberto Alvaro de Oliveira**
}

\section{RESUMEN}

El derecho a la tutela jurisdiccional es tratado en el presente trabajo tomándose en cuenta los valores de efectividad y de seguridad en una perspectiva dinámica. Dichos valores son considerados asimismo como derechos fundamentales en el contexto del Derecho Procesal Civil y de la Constitución brasileña.

SEGURIDAD - DERECHOS FUNDAMENTALES - PROCESO CIVIL

\section{The right to effective jurisdictional guardianship from a fundamental law perspective}

Abstract

The essay seeks to establish a concept of effectiveness and security within a dynamic perspectiv, considering these two values to be fundamental rights, within the context of civil procedural law and the Brazilian Constitution.

SECURITY - FUNDAMENTAL RIGHTS - CIVIL PROCEDURAL LAW

* Este trabajo fue expuesto en las XXI Jornadas Iberoamericanas organizadas por el Instituto Iberoamericano de Derecho Procesal llevadas a cabo en Lima, Perú, el 16 de octubre de 2008.

** Abogado, Doctor en Derecho, Profesor Titular de Derecho Procesal Civil en la Facultad de Derecho de la Universidad Federal do Río Grande do Sul, Porto Alegre, Brasil. Artículo recibido el 29 de diciembre de 2008 y aceptado para su publicación el 18 de mayo de 2009. 


\section{INTRODUCCIÓN}

$\mathrm{E}$ n relación al derecho a la tutela jurisdiccional efectiva desde la perspectiva de los derechos fundamentales, debo advertir que no vislumbro cómo pueda abordar el tema de la efectividad sin considerar también la seguridad que el proceso debe proporcionar al litigante. No hay noche sin día, verano sin invierno, o cielo sin infierno. No adelantaré mi posición en orden a considerar la efectividad del cielo o la seguridad el infierno. Sólo destaco por ahora que ambos conceptos son indisociables, aunque la moda actual sea realzar la efectividad a la que se prestan todos los homenajes. Al final de la exposición quedará clara mi posición al respecto.

Dicho eso, expresaré que la supremacía constitucional del derecho fundamental acarrea innumerables consecuencias en el dominio del proceso civil.

No obstante la regulación legal del proceso y las determinantes consitucionales que lo conforman, así como el formalismo ahí implicado, puede ocurrir un desfase en relación con las necesidades sociales. También es posible que, frente a las peculiaridades del caso concreto, la aplicación de la regla dificulte la realización del derecho material, conduciendo a una situación injusta y no deseada por el sistema constitucional y los valores imperantes en una determinada sociedad. Por otro lado, el empleo de determinadas técnicas, previstas en la ley, puede revelarse insastisfactorio en términos de justicia, efectividad, seguridad, igualdad y otras determinantes axiológicas y deontológicas de carácter constitucional.

En todas esas hipotésis, los derechos fundamentales constituirán un soporte importante para la integración y superación de las dificultades presentadas por el sistema, colaborando así, de forma decisiva, para una aplicación más justa del derecho.

Con base en esas premisas, partiendo del plano axiológico en que se sitúan seguridad y efectividad, pretendo elaborar en lo que sigue, en un plano deontológico, los dos derechos fundamentales que se vinculan con aquellos valores: el derecho fundamental al proceso justo y el derecho fundamental a una tutela jurisdiccional revestida de efectividad calificada.

\section{EvOluCiÓN DEL PROBLEMA}

Algunos aspectos son importantes de resaltar para una mejor comprensión del problema. En primer lugar, la ascensión de los derechos de los ciudadanos frente al Estado absolutista, factor determinante para el surgimiento del Estado Liberal, de que es precursora en el plano jurídico la teoría de los derechos subjetivos públicos de Jellinek. Después, importa destacar el descenso del normativismo legalista, con la formación del Estado democrático de derecho y la elaboración de la teoría de las normas de principio y el fortalecimiento de los derechos fundamentales constitucionales. Esos elementos históricos permitirán comprender mejor el tema central de mi exposición.

\section{a) La teoría de los derechos públicos subjetivos}

La teoría de los derechos públicos subjetivos mantiene estrecha conexión con la caracterización liberal de los derechos y la construcción jurídica del Estado constitucional moderno, en su búsqueda de igualdad formal. 
El desarrollo de esa concepción se debe principalmente a Georg Jellinek (1892) quien centró la nota distintiva del Estado moderno en el reconocimiento del individuo como persona y como sujeto de derecho, apto para reclamar con eficacia la tutela jurídica del Estado. El simple hecho del individuo de pertenecer al Estado se muestra relevante desde el punto de vista jurídico en las relaciones mantenidas entre los dos. En esa perspectiva, las pretensiones jurídicas que resultan de tales condiciones son lo que se designa por derechos subjetivos públicos. Estos consisten, así, en "pretensiones jurídicas (Ansprüche) frente al Estado, resultantes directamente de situaciones o condiciones (Zustände) jurídicas”. ${ }^{1}$

No es difícil comprender que la teoría de los derechos públicos se revela indisociable de la tutela jurisdiccional de los derechos. Basta poner atención en que la pretensión de otorgamiento de jurisdicción, dirigida contra el Estado como titular de la soberanía, no constituye un simple efecto reflejo del derecho objetivo. Y eso porque el deber del Estado de otorgar jurisdicción no se centraliza sólo en el interés general, sino especialmente en el interés de quien busca la satisfacción de su (afirmado) derecho delante del órgano judicial. ${ }^{2}$ Además, el otorgamiento de jurisdicción no es un arbitrio del órgano judicial, sino que más bien ella es entendida como una protección imperativa (aunque pueda ser favorable o desfavorable) y no meramente aleatoria. El juez actual no puede eximirse de prestar jurisdicción con el non liquet (no está claro), como ocurrió en determinada fase del derecho romano. ${ }^{3}$

Se trata, no hay duda, de un momento asaz significativo del movimiento cultural que buscaba una reacción contra los poderes extremados de los Estados absolutos, visando la defensa de las libertades de los ciudadanos con un adecuado sistema de garantías y aún creando un nuevo Estado de derecho en que imperase la igualdad formal. ${ }^{4}$

En ese panorama se inserta ${ }^{5}$ la elaboración en el siglo XIX y en los primeros años del siglo pasado del derecho de acción, que como categoría atípica permitió reconciliar, de forma automática y necesaria, el derecho material (todos los derechos materiales) y la tutela jurisdiccional civil, colaborando así para la superación de los límites intrínsecos de la tipicidad de las acciones del derecho romano clásico. Tal consecuencia, sin embargo, aunque pueda haber sido benéfica en determinada época, ya no es satisfactoria. Y eso porque, hoy, la constitucionalización del derecho de acción -ocurrida en un contexto normativo referido a la superación de la igualdad formal- impone la necesidad de eliminar las consecuencias causadas por el quiebre creado entre el derecho material (derechos

${ }^{1}$ Jellinek, G., System der subjektiven öffentlichen Rechte, Tübingen, J.C.B Mohr (Paul Siebeck), $2^{\mathrm{a}}$ ed. 1905, y la exposición y ponderaciones formuladas por Jorge Reis Novais, Contributo para uma teoria do Estado de Direito, Coimbra, 1978, separata del volumen 24 del Suplemento ao Boletim da Faculdade de Direito da Universidade de Coimbra, p. 79-80

${ }^{2}$ Vid. Reis Novais, J., Contributo, cit., p. 81.

3 Vid. Nakano, T., Das Prozessrechtsverbältnis, Zeitschrift für Zivilprozess, 79 (1966): 99-113, esp. p. 108.

${ }^{4}$ Vid. Casetta, E., Diritti pubblici subiettivi, Enciclopedia del diritto, Milano, Giuffrè, 1964, vol. 12, p. 792 .

${ }^{5}$ Vid. Proto Pisani, A., Lezioni di diritto processuale civile, 6a ed., Napoli, Jovene, 2006, pp. 51-53. 
materiales individualmente considerados) y el proceso, con el estudio de técnicas que permitan a este último desempeñar su función institucional de instrumento dirigido a dar en cuanto sea posible desde un punto de vista práctico, a quien tiene un derecho, todo aquello que él tiene derecho a conseguir materialmente, como ya apuntara de forma innovadora Chiovenda en $1911 .{ }^{6}$ Es de percibir que el gran maestro no se refería al factor tiempo, poco relevante en la época en que escribía.

En realidad, el problema del constitucionalismo de los días actuales no es más el de reivindicar una posición formal de autonomía del ciudadano en sus relaciones con el poder estatal, tal como era exigido por la concepción de Estado liberal, ni incrementar sólo la igualdad formal. Se trata ahora de asegurar al ciudadano la posibilidad de defender en concreto tales posiciones delante del poder público, en busca de una igualdad material, en consonancia con la idea fuerza del "welfare state". El derecho no puede ser concebido sólo como un sistema de imperativos dispuestos por la voluntad del Estado en defensa de las esferas de libertad del individuo. En un orden de valores muy distinto en comparación con la sociedad del siglo XIX y a la luz de los principios constitucionales fundamentales de igualdad material, seguridad y dignidad social, de solidaridad y de utilidad social, el derecho viene a ser considerado ahora como factor institucional de la vida económica y social, vale decir, como instrumento de potencialización y de impulso de la personalidad individual y de realización de relaciones sociales más ecuánimes, para la tutela, no sólo formal, sino substancial, de la dignidad y del desarrollo del hombre en el ámbito de la comunidad. ${ }^{7}$

Por otra parte, una de las limitaciones de la concepción ahora criticada está en su carácter esencialmente estático, donde la garantía sirve exclusivamente como mero derecho de defensa del ciudadano frente al poder estatal.

En el proceso, la visión estática condujo a una simple constitucionalización formal de los principios procesales ya existentes, cuyos efectos se agotarían por completo en un encuadre de garantía, pero sin llegar a interferir directamente, de forma innovadora, sobre la realidad del proceso. Sintomáticamente, en los años cincuenta del siglo XX, cuando empezó de forma sistemática el estudio de las relaciones entre proceso y Constitución, poco se hablaba, por ejemplo, de la garantía de efectividad.

Vale resaltar que tal concepción circunscribió el objeto de las "garantías constitucionales" al "debido proceso legal” (con su corte de garantías correlatos: contradictorio, amplia defensa, juez natural, etc.), y este a su vez estaría detallado en la legislación infraconstitucional. De tal modo, en el fondo, la "garantía” del "debido proceso legal" sería establecida a partir de la legislación infraconstitucional, punto de vista que impedía

${ }^{6}$ Cfr. Chiovenda, G., Della azione nascente dal contratto preliminare, ensaio publicado en 1911 en la Rivista di Diritto Commerciale, compilado en los Saggi di Diritto Processuale Civile, Roma, Foro Italiano, 1930, vol. 1, pp. 101-119, esp. p. 110.

${ }^{7}$ Esas consideraciones son de Marco Comporti, Diritti reali in generale, Trattato di diritto civile e commerciale (coord. de Cicu, Messineo e Mengoni), vol. 8, t. 1, Milano, Giuffrè, 1980, p. 16 e nota 33, con amparo de harta bibliografía. Sin perjuicio de que aparezcan dirigidas al derecho material, encuentran también amplia aplicación, mutatis mutandis, en el campo del derecho procesal. 
o por lo menos dificultaba la relectura de las normas infraconstitucionales a partir de los derechos fundamentales. ${ }^{8}$ Además, tal manera de mirar el problema no daba espacio a la construcción de instrumentos capaces de llenar las lagunas de la regla, aplicando principios constitucionales.

\section{b) La declinación del normativismo legalista}

El panorama empezó a cambiar con las profundas transformaciones ocurridas en la lógica jurídica, a mediados del siglo pasado, a partir de las aportaciones de Viehweg, Giuliani, Perelman y otros, así como con la aparición de la teoría de los principios elaborada por Dworkin y el fortalecimiento de los derechos fundamentales, frente de las necesidades del Estado providencia. Esos factores fueron determinantes para la declinación del normatismo legalista, bandera asumida por el positivismo jurídico, que hizo que las normas de principio, conceptos jurídicos indeterminados y juicios de equidad, pasasen a asumir una posición relevante en la aplicación del derecho.

Esa nueva visón contribuye, por supuesto, a que la decisión judicial sea elaborada no solo partiendo de un prius anterior al proceso, sino también con base en los propios elementos que en él serán recogidos. Ello acarreó una disminución del valor de la seguridad, reduciendo asimismo la previsibilidad en cuanto al desarrollo del proceso y de la sentencia judicial, incrementando en consecuencia el peligro de colisión entre los derechos de libertad y las posiciones que los derechos fundamentales ocupan en el mundo actual. Todo eso se potencializa porque los derechos fundamentales exhiben gran fuerza de propagación sobre el derecho legislado, al acentuar todavía más el papel del juez en el "descubrimiento" del derecho con su tarea de adaptación al caso concreto.

\section{c) El papel de los derechos fundamentales}

En realidad, ya no se discute mayormente en la doctrina constitucional el papel de los derechos fundamentales y de las normas de principio -igualmente, de las consideradas simplemente programáticas- entendidas como directivas materiales permanentes, que vinculan positivamente a todos los órganos encargados de la jurisdicción, que deben tenerlas en consideración en cualesquiera de los momentos de su actividad. ${ }^{9}$ De otro

${ }^{8}$ En el mismo sentido, la crítica de Comoglio, L. P., Lezione Sul Processo Civile (en colaboración con Corrado Ferri y Michele Taruffo), $2^{\mathrm{a}}$ ed., Bologna, Il Mulino, 1999, p. 56. Debe observarse que, al enfrentar esa problemática, exactamente en un caso en que estaba en juego la cláusula del due process of law, la $2^{\mathrm{a}}$ Sala del Supremo Tribunal Federal, órgano máximo de la justicia brasileña (RE 194.295-9 - RJ, rel. Ministro Marco Aurélio, j. en 07.11.2000, DJU de 17.08.2001, v.u., Revista dos Tribunais 799 (mai/2002) 174-176), adoptó una postura menos formalista y admitió el recurso para examen del texto constitucional. Ese nuevo entendimiento concibe insubsistente la tesis de que, para el conocimiento del recurso extraordinario, la ofensa a la Carta Política de la República ha de ser directa y frontal, adoptando una posición tópica: el examen debe ser caso por caso.

${ }^{9}$ Vid. Gomes Canotilho, J. J., Direito Constitucional, 4 a ed., Coimbra, Almedina, 1987, p. 132. 
modo, la más importante fuente jurídica de las normas de principio son exactamente los derechos fundamentales.

Por otra parte, la concepción de los derechos fundamentales como normas objetivas supremas de la ordenación jurídica vuelve a revestir fundamental importancia práctica y no solo teórica para las tareas del Estado. Por eso, cualquier poder del Estado tiene una obligación (negativa) de abstenerse de injerir en el ámbito protegido por los derechos fundamentales, como también una obligación (positiva) de llevar a cabo todo aquello que sirva para la realización de esos derechos, incluso cuando no se refieran a una pretensión subjetiva de los ciudadanos. ${ }^{10}$

\section{d) Conclusiones parciales}

Las anteriores consideraciones muestran cómo nos hemos alejados de la concepción tradicional, que consideraba a los derechos fundamentales instrumentalizados sólo como garantías de defensa del ciudadano frente al Estado, y no como los entiende la más reciente doctrina: como derechos constitutivos institucionales, con una amplia y fuerte potencialización.

En realidad, los jueces y los demás operadores jurídicos tienen el deber de aplicar los preceptos constitucionales derivando de esto la autorización para que haya una concreción por vía interpretativa, ${ }^{11}$ ámbito de actuación que todavía adquiere más flexibilidad frente a la moldura desvanecida de la norma de principio. $^{12}$

La cuestión se revela con una particular importancia para el ejercicio de la ciudadanía por la vía jurisdiccional, visto que de esa forma se atribuye al individuo el poder de ejercer positivamente los derechos fundamentales (libertad positiva) y de exigir omisiones de los poderes públicos, de modo de evitar agresiones lesivas por parte de éstos (libertad negativa). ${ }^{13}$

Desde el punto de vista de los que ejercen el Poder Judicial, el aspecto relevante es que en esa normativa de carácter esencialmente principiad se encuentra contenido un auténtico otorgamiento de competencia para una investigación más libre del derecho. Aquí, la particularidad, en relación a otros tipos de normas jurídicas, es que la competencia

${ }^{10}$ Vid. Hesse, K. Significado de los derechos fundamentales, in Manual de Derecho Constitucional, $2^{\text {a }}$ ed., trad. Antonio López Pina, Madrid, Marcial Pons, 2001, p. 95.

${ }^{11}$ Observa, acertadamente, Vieira de Andrade, J. C. Os Direitos fundamentais na Constituição portuguesa de 1976, Coimbra, Almedina, 1987, p. 256, que en la falta de ley que concrete determinado derecho fundamental, "el principio de la cualidad de lo que es aplicable directamente vale como indicador de ejecutabilidad inmediata de las normas constitucionales, presumiéndose su perfección, esto es, su autosuficiencia basada en el carácter líquido y cierto de su contenido de sentido. Van, pues, aquí, incluidos el deber de los jueces y de los demás operadores jurídicos de aplicar los preceptos constitucionales y la autorización para, con ese fin, concretarlos por vía interpretativa".

12 Examen de la evolución del problema en el derecho alemán por Alexy, R. Direito Constitucional e Direito Ordinário. Justiça Constitucional e Justiça Especializada, trad. Luís Afonso Heck, Revista dos Tribunais, 799 (maio/2002) p. 33-51.

13 Vid. Gomes Canotilho, J. J. Direito Constitucional, cit., p. 448. 
para el descubrimiento del derecho en el caso concreto se la vincula con los principios de manera amplia e indeterminada. ${ }^{14}$ La constatación se muestra verdaderamente relevante en la medida en que, estando constitucionalmente facultado el ejercicio de un derecho producido por los jueces, se legitima la actividad creativa del Poder Judicial delante de la sociedad como un todo, igual que frente a la resistencia de intereses contrariados.

Frente a esa línea evolutiva, la participación en el proceso no puede ya ser vista solamente como instrumento funcional de democratización o realizador del derecho material y procesal, sino que se debe ponderar su valor intrínseco, complementario y que integra esas mismas esferas. El proprio proceso pasa así a ser el medio de formación del derecho, sea material o procesal, lo que se ve incrementado por la constatación de que el proceso debe servir para la producción de decisiones conforme a la ley; pero, además, dentro del marco de esa corrección, sirve esencialmente para la producción de decisiones justas. ${ }^{15}$

\section{EFECTIVIDAD Y SEGURIDAD EN PERSPECTIVA DINÁMICA}

Las ideas hasta ahora alineadas evidencian la necesidad de centrar el análisis en una perspectiva de derecho constitucional, en vista de que en ese nivel se sitúa el núcleo resistente tanto del derecho fundamental de acceso a la jurisdicción como del derecho al proceso justo y a la efectividad de la tutela jurisdiccional.

Con la constitucionalización de la tutela jurisdiccional de los derechos, el eslabón entre el derecho material y el procesal se da por medio del derecho fundamental constitucional de tutela, utilizando como herramienta el otorgamiento de jurisdicción y la respectiva pretensión (ambos situados en el plan del derecho público). Por eso, las funciones ordenadora y pacificadora del derecho infraconstitucional dependen en gran medida de que se impongan, cuando es necesario, por vía ejecutiva, mediante coerción estatal. Su observancia, pues, siempre resulta asegurada desde fuera. ${ }^{16}$

En la visión dinámica, que emana de la teoría de los principios, con su inherente plasticidad, incumbe a los derechos fundamentales precisar los contenidos mínimos del llamado "derecho al proceso". Y ese derecho fundamental no se limita tan solo al acto

${ }^{14}$ Vid. Meier, I., Auflösung des geschriebenen Rechts durch allgemeine Prinzipiennormen, in Prinzipiennormen und Verfahrensmaximen, en colaboración con Rudolf Ottomann. Zürich, Schulthess Verlag, 1993, pp. 56-58.

${ }^{15}$ Así, Alexy, A.,Teoría general de los derechos fundamentales, trad. Ernesto Garzón Valdés, Madrid, Centro de Estudios Constitucionales, 1997, p. 472, quien resume la posición del Tribunal Constitucional Federal alemán. A respecto del punto, véase Carlos Alberto Alvaro de Oliveira, Del formalismo en el processo civil (Propuesta de un formalismo valorativo), trad. Prof. Juan José Monroy Palácios, $3^{\mathrm{a}}$ ed., Lima, Palestra Editores, 2007 , pp. 142-143. Es de observar que uno de los valores supremos del orden constitucional brasileño es la justicia, como se resalta en el Preámbulo de la Constitución de la República de 1988.

16 Vid. Hesse, K., Constitución y Derecho Constitucional, en Manual de Derecho Constitucional, cit., p. 8. Ocurre lo contrario, prosigue, con las normas constitucionales, pues su observancia no es garantizada ni por una ordenación jurídica existente por encima de ellas, ni por una coactividad supraestatal; la Constitución no depende sino de su propia fuerza y de sus propias garantías. 
inicial del juicio, sino que abarca a todas las posiciones "activas" de las partes a lo largo de todo el procedimiento, hasta el acto final.

Desde este punto de vista, cabe al proceso la función primaria de codificar la relación fundamental entre la iniciativa del individuo para la instauración del proceso (principio dispositivo en sentido material ) y la posibilidad de obtenerse en juicio una tutela jurisdiccional adecuada (adecuación, veremos después, significa proporcionalidad entre efectividad y seguridad). Lo importante es que la constitucionalización del derecho al proceso y a la jurisdicción (a ejemplo del artículo $5^{\circ}$, inciso XXXV, de la Constitución brasileña), aliada al derecho fundamental de efectividad y a un proceso justo (artículo $5^{\circ}$, incisos XXXVII, LIII, LIV, LV, LVI, LX y LXXVIII, de la Constitución brasileña), determina también una garantía "de resultados”, resaltando el nexo teleológico fundamental entre "actuar en juicio" y la "tutela" jurisdiccional del derecho afirmado.

Se trata de un derecho fundamental e inviolable por parte de los poderes estatales, ${ }^{17}$ pues asegurado el acceso a la jurisdicción, en caso de lesión o amenaza de lesión al derecho (vale en cuanto afirmada tal lesión), constituiría una evidente incongruencia que no se comprendiera también el ejercicio del derecho de invocar y obtener tutela jurisdiccional adecuada y efectiva. ${ }^{18} \mathrm{El}$ derecho fundamental de acceso a la jurisdicción se traduce entonces en el poder de exigir del órgano judicial, en tiempo razonable, el desarrollo completo de sus actividades, tanto decisorias, con emisión de un pronunciamiento procesal o de mérito sobre el objeto de la pretensión procesal, como que pueda ser realizado efectivamente desde el punto de vista material. ${ }^{19}$ Todo eso debe conformarse al concepto de adecuación, con la proporcionalidad necesaria entre el derecho fundamental a un proceso justo y el derecho fundamental a una tutela jurisdiccional efectiva y adecuada. ${ }^{20}$

Frente a la constitucionalización de las normas fundamentales sobre el acceso al proceso y el proceder en juicio, así como sobre los resultados de la actividad jurisdiccional, pierde consistencia teórica la vieja y superada categoría de la "acción".

${ }^{17}$ Vid. Baur, F., Der Anspruch auf rechtliches Gebör, in Beiträge zur Gerichtsverfassung und zum Zivilprozessrecht, Tübingen, J. C. B. Mohr (Paul Siebeck), 1983, pp. 85-86. Se nota, con todo, que su elaboración doctrinaria partió de una interpretación extensiva del artículo 103 de la Ley Fundamental de Bonn, dispositivo que solo garantiza el principio de la audiencia (contradictorio), lo que le valió la crítica de Nicolò Trocker, Processo Civile e Costituzione - Problemi di diritto tedesco e italiano, Milano, Giuffre, 1974, pp. 170-171. El derecho constitucional brasileño, sin embargo, no se sujeta a esa censura porque se muestra, en el punto, superior al sistema alemán, visto que de forma expresa garantiza el acceso a la jurisdicción y al debido proceso legal.

18 Vid. Baur, F., Der Anspruch auf rechtliches Gehör, cit., pp. 86-87.

19 Idea defendida por Baur, F., Der Anspruch auf rechtliches Gebör, cit., p. 91, en relación al derecho alemán, y con mucho mayor razón aplicable en el sistema jurídico brasileño, en vista de una mayor amplitud de éste, como antes fue explicado.

${ }^{20}$ Vid. Gomes Canotilho, J. J., Direito Constitucional, cit., p. 276, hablando sobre el principio de la garantía de la vía judiciaria, preconiza que "Eso presupone que, al lado de la creación de los procesos legales aptos para garantizar esa defensa, se abandone a la clásica ligación de accionabilidad, al derecho subjetivo y se pase a incluir en el espacio subjetivo del ciudadano todo el círculo de situaciones juridicamente protegidas. El principio de la protección jurídica fundamenta así una anchura de la dimensión subjetiva, y sostiene, al mismo tiempo, un verdadero derecho o pretensión de defensa de las posiciones jurídicas ilegalmente lesionadas (...)”. 
En efecto, se impone desmitificar tanto la acción procesal cuanto la posibilidad de reacción del demandado, pues la deseable efectividad del proceso depende en lo esencial de la dimensión de los poderes de las partes y de los poderes/deberes del órgano judicial, de la conformación y adecuación del procedimiento, de técnicas más apropiadas y de las formas de tutela jurisdiccional, en la medida en que todos esos elementos se muestran realmente significativos para una mejor realización de los valores fundamentales del proceso.

Además, es imposible olvidar algunos factores externos al sistema procesal, entre los cuales el exceso de causas en el sistema, la composición numérica adecuada de los cuadros que administran justicia, procuradores, funcionarios de la justicia, peritos, etc.; y principalmente de una mentalidad que no sea solo tecnoburocrática, sino que esté empeñada en la realización de los valores fundamentales del proceso y de la Constitución.

Por lo tanto, para obtener una efectividad calificada no es suficiente una reelaboración de la acción procesal, ${ }^{21}$ atípica por definición, sino establecer medios y procedimientos adecuados, de conformidad con técnicas mejor predispuestas a la realización de los derechos, y, principalmente, tutelas jusrisdiccionales seguras y eficientes en cuanto adecuadas. El actuar, la acción (o la reacción), será seguramente la consecuencia de todo eso, antes que su presupuesto. Además, tal modo de pensar olvida los actos propios del oficio del juez, aspecto que escapa al simple actuar de las partes. Considerados estos factores, entiendo mucho más correcto hablar de un derecho a un proceso adecuado y a una tutela adecuada, antes que a una acción adecuada, porque solo así será posible tener en consideración los elementos culturales, los valores (especialmente de orden constitucional) y los derechos fundamentales propios de cada agrupación social, con atención a las normas de principio de la seguridad y de la efectividad y el empleo de técnicas que permitan una realización del derecho más apropiada al caso concreto.

La efectividad calificada, en una perspectiva dinámica, implica, en primer lugar, el derecho de la parte a la posibilidad seria y real de obtener del juez una decisión de mérito, alejándose, siempre que sea posible, de los obstáculos formales que impidan esa finalidad. ${ }^{22}$ Además, la efectividad calificada exige que la tutela jurisdiccional se adapte a la naturaleza de las situaciones subjetivas tutelables, de manera que sea plenamente satisfecha la "necesidad de proteción" manifestada en la demanda. Por tanto, es muy deseable que las formas de tutela sean elásticas y diferenciables, teniendo en cuenta las peculiaridades de las crisis sufridas por el derecho material y las exigencias del caso concreto. Incluso, es importante que concedan el máximo de efectividad, para que sean preservados otros derechos fundamentales, en especial el derecho al proceso justo, que

${ }^{21}$ Propuesta estimable, pero insuficiente a mi ver, de Marinoni, L. G., Da ação abstrata uniforme à ação adequada à tutela dos direitos, in Polêmica sobre a ação - A tutela jurisdicional na perspectiva das relações entre direito e processo, orgs. Fábio Cardoso Machado e Guilherme Rizzo Amaral, Porto Alegre, Livraria do Advogado Editora, 2006, pp. 197-252.

${ }^{22}$ El tema fue examinado con gran sutileza por Bedaque, J. R. en su tesis de titularidad, Efetividade do processo e técnica processual: tentativa de compatibilização, São Paulo, Malheiros, 2006, passim. 
es la concreción deontológica del valor de la seguridad en el Estado constitucional y demócratico de derecho. ${ }^{23}$

Eso significa no solo alejar en la medida de lo posible la tipicidad de las formas de tutela, sino también dar flexibilidad al sistema de tutela, a fin de incluir todas las formas de derecho material (derecho individual o colectivo, condenación, declaración, mandamiento y ejecución), ${ }^{24}$ así como asegurar formas represivas o preventivas, de modo de asegurar totalmente la exigencia de adecuación. ${ }^{25}$ También es indispensable que la tutela pueda reflejarse efectivamente en el mundo social. No solo basta declarar la existencia del derecho, sino realizarlo de hecho, cuando sea necesario.

Teniendo presente esas coordenadas, el legislador reformador del proceso civil brasileño, inspirado, supongo, en la doctrina innovadora de Pontes de Miranda, con la convicción de una efectividad virtuosa, adoptó de manera expresa dos formas de tutela jurisdiccional ignoradas por la doctrina europea: la tutela de mandamiento (artículo 461 del Código Procesal Civil) y la tutela ejecutiva lato sensu (artículo 461-A del Código Procesal Civil). Ambas constituyen elementos diferenciadores del sistema jurídico brasileño en el ámbito del derecho civil law, aspecto que de ninguna manera puede ser olvidado cuando se lee doctrina extranjera, condicionada por otras determinantes normativas y distintas realidades culturales.

En la perspectiva del derecho fundamental de efectividad, es necesario interpretar esos dispositivos con mirada amplia, aplicando las formas de tutela ahí previstas a otras situaciones semejantes. Por ejemplo: el citado artículo 461 debe incidir también en la protección de los derechos absolutos, en que no existe obligación de hacer o no hacer, y sí deber por parte de todos los miembros de la comunidad (ejemplo: respeto a los derechos de personalidad). De igual manera, el deber de restitución del bien que un tercero se apropió con ilegalidad, aunque no configure obligación de dar, está al abrigo de la tutela ejecutiva lato sensu asegurada en el artículo 461-A (ejemplo: la llamada acción "reivindicatoria").

Tampoco puede ser rechazada a priori la aplicación de la técnica de las astreintes en la ejecución de obligación de pago; aun en el silencio de la ley procesal, es necesario su empleo en el caso concreto, para asegurar el núcleo esencial del derecho fundamental a la tutela jurisdiccional efectiva. ${ }^{26}$ En realidad, la llamada máxima de la prohibición de

${ }^{23}$ Sobre el significado de Estado constitucional y especialmente las peculiaridades del sistema brasileño, Mitidiero, D., Processo civil e Estado constitucional, Porto Alegre, Livraria do Advogado ed., 2007, pp. 15-30.

${ }^{24}$ Específicamente, el derecho procesal brasileño admite tutela de mandamiento, en la cual prevalece el orden del juez, y la llamada tutela ejecutiva lato sensu, en que en la propia fase de conocimiento pueden ser adoptadas medidas de carácter ejecutivo (v.g., Mandado de Seguridad contra actos del Poder Público, Ley $\mathrm{N}^{\circ} 1.533$, de 31/12/1951; arts. 14, 461 y 461-A del Código Procesal Civil).

${ }^{25}$ En la misma línea de pensamiento, observa con razón Marinoni, L. G., Técnica processual e tutela dos direitos, São Paulo, Revista dos Tribunais, 2004, pp. 30-31, que el juez debe estar atento a los derechos fundamentales y "así no puede cruzar los brazos delante de la primera impresión de insuficiencia de la ley procesal, aunque deba siempre considerar el derecho de defensa”.

26 Al tiempo que ejercía la judicatura, adopté ese entendimiento en el juzgamiento de la Acción Rescisoria 599263183, TJRS, 6a Cámara Civil, j. en 26.4.2000. En el mismo sentido opina Marinoni, L. G. 
insuficiencia autoriza al juez a integrar las lagunas de protección, pues si no se alcanza la eficacia esperada del derecho fundamental, su núcleo esencial podría ser destruido. ${ }^{27}$

Es interesante constatar la línea evolutiva en el ámbito de la tutela jurisdiccional ocurrida en el derecho brasileño a partir de la idea de acción como accesorio de derecho material, de que era ejemplo el artículo 75 del arcaico y revocado Código Civil brasileño de 1916, según el cual "a todo derecho corresponde una acción, que la asegura".

El artículo 83 del Código de Defensa del Consumidor brasileño (Ley n ${ }^{\circ}$ 8.078, de 11/09/1990) al estatuir que "para la defensa de los derechos e intereses protegidos por este código son admisibles todas las especies de acciones capaces de propiciar su adecuada y efectiva tutela" representa ya una concepción no solo unida a la acción abstracta, sino que anticipa de cierta manera las ideas defendidas aquí.

Esas ideas podrían ser sintetizadas de forma normativa por la siguiente prescripción: "para la efectiva realización de los derechos, son asegurados un proceso justo y las tutelas jurisdiccionales adecuadas". Trátase de una norma constitucional que puede ser extraída de textos presentes en el sistema constitucional brasileño, vinculada a una comprensión de tutela jurisdiccional comprometida tanto con la efectividad cuanto con la seguridad; a esto se debe la mención a la "efectiva realización de los derechos", "proceso justo" y "tutela adecuada".

Con esa referencia al proceso justo, introduzco en el discurso la cuestión de la seguridad, que es la otra cara de la efectividad, como adelanté en el inicio de mi exposición.

Observo, en primer lugar, que el cambio de paradigma que transcurre del paso del normativismo legalista al derecho fundamental de carácter de principio, afecta de manera igual la seguridad jurídica, que deja de ser estática en la medida que pasa a convivir con un derecho mucho más flexible y menos rígido.

De tal forma, hoy la seguridad jurídica de una norma debe ser medida por la estabilidad de su finalidad, abarcada en caso de necesidad por su propio movimiento. No se busca más el absoluto de la seguridad jurídica, sino la seguridad jurídica afectada de un coeficiente, de una garantía de realidad. En esa nueva perspectiva, la propia seguridad jurídica induce al cambio, al movimiento, visto que debe estar al servicio del objetivo mediato de permitir la efectividad del derecho fundamental. ${ }^{28}$ En suma, la seguridad ya no es vista con los ojos del Estado liberal, en que tendía a prevalecer como valor, porque no sirve más a los fines sociales a que se destina el Estado. Dentro de estas coordenadas, el juez debe estar atento a las peculiaridades del caso, pues atendiendo incluso el for-

Técnica processual e tutela dos direitos, cit., pp. 216-217, mencionando la resolución y resaltando con propiedad que "la omisión del legislador en dar efectividad al derecho fundamental a la tutela jurisdiccional efectiva, como es muy claro, no puede ser interpretada en su disfavor".

${ }^{27}$ Vid. Scherer de Mello Aleixo, P., O direito fundamental à tutela jurisdicional efetiva na ordem jurídica brasileira (a caminho de um "devido processo proporcional"), separata de Direitos fundamentais e direito privado - uma perspectiva de direito comparado, Coimbra, Almedina, 2006, pp. 432-433, refiere, en abono de la tesis, decisión del Tribunal Constitucional Federal alemán, al alertar que el núcleo esencial de los derechos fundamentales puede correr riesgo "cuando fuese impedido de ser efectivo en el proceso de manera eficaz".

${ }^{28}$ Véase al respecto la excelente elaboración doctrinaria de Boursier, M-E., Le principe de loyautè en droit processuel, Paris, Dalloz, 2003, n. ${ }^{\circ} 679$, p. 408. 
malismo establecido por el sistema, de cara a las circunstancias de la especie, el proceso puede presentarse injusto o llevar a un resultado también injusto.

En realidad, la visión estática afirmaba la seguridad en la garantía del "debido proceso legal" (artículo $5^{\circ}$, inciso LIV, de la Constitución de la República). Sin embargo, en una visión dinámica, ligada a los principios y a los derechos fundamentales, parece más correcto hablar de un derecho fundamental a un proceso justo. En semejante perspectiva, no se trata de un genérico derecho al proceso, asentado en derechos estáticos, sino que se intenta asegurar, a partir de los conceptos de ecuanimidad y de justicia, no sólo la suficiencia cuantitativa mínima de los "medios procesales", sino también un "resultado" cualitativamente diferenciado. De esa manera, a partir de las premisas anteriormente establecidas es posible extraer la consecuencia de que, en el cuadro de los derechos fundamentales constitucionales, el "derecho al proceso" no se caracteriza por un objeto únicamente formal o abstracto ("proceso" tout court), sino que asume un contenido modal calificado ("derecho al justo proceso"), que es exactamente la cara dinámica del "debido proceso legal”. ${ }^{29}$ En semejante contexto, la estricta perspectiva de un "debido proceso legal", correspondiente a una comprensión claramente liberal y que afirma como cierto el fenómeno jurídico, debe ser comprendida a partir de una visión dinámica en que todos los institutos y categorías jurídicas son leídas una vez más a la luz de la Constitución y en la cual el proceso civil es materialmente informado por los derechos fundamentales. ${ }^{30}$

De tal modo, el concepto del proceso justo proviene, en primer lugar, de la comprensión concreta de ciertos derechos fundamentales expresos, a ejemplo de la prohibición de juicios de excepción y del principio del juez natural (artículo $5^{\circ}$, incisos XXXVII y LIII, de la Constitución brasileña), del contradictorio y de la amplia defensa, con los medios y recursos a ella inherentes (artículo $5^{\circ}$, inciso LV, de la Constitución brasileña), de la inadmisibilidad de las pruebas obtenidas por medios ilícitos (artículo $5^{\circ}$, inciso LVI, de la Constitución brasileña), y del derecho fundamental la decisión verdaderamente fundamentada (artículo 94, inciso IX, de la Constitución brasileña). Además, la visión con carácter de principio, al contrario de la estática y garantista, no se limita a los derechos fundamentales expresos y puede elaborar normas a partir de otros derechos fundamentales de principios, contenidos en la Constitución, con vistas a la concreción de un proceso justo y una tutela jurisdiccional efectiva.

Un ejemplo emblemático es el principio de la igualdad (artículo $5^{\circ}$, caput de la Constitución brasileña), que permite establecer la noción de proceso ecuánime y, en consecuencia, la norma de principio o el derecho fundamental de la paridad de armas. Vale decir, la parte debe tener la posibilidad razonable de presentar su causa en condiciones tales que no la ponga en situación de desventaja en relación a la otra. ${ }^{31}$

${ }^{29}$ Vid. Comoglio, L. P., Lezioni sul processo civile, cit., pp. 58-60.

${ }^{30}$ En el mismo sentido, Scherer de Mello Aleixo, P., $O$ direito fundamental à tutela jurisdicional efetiva, cit., p. 428.

${ }^{31}$ Esa comprensión es derivada de la jurisprudencia de la Corte Europea de los Derechos del Hombre. V.g., arestos Dombo Beheer B.V. vs. Países Bajos, de 27.10.1993, serie A, n²74, § 33, Bulut v. Austria, de 22.2.1996, Recueil 1996, II, § 47 Foucher vs. Francia, de 17.3.1997, § 34, Kuopila vs. Finlandia de 


\section{LA DIMENSIÓN DEL CONFLICTO ENTRE EFECTIVIDAD Y SEGURIDAD Y SU RESOlUCIÓN. El PAPEL DE LA ADECUACIÓN. CONSIDERACIONES CONCLUSIVAS}

No puedo concluir esta exposición sin abordar el tema principal de las líneas de confluencia entre los derechos fundamentales de la efectividad y de la seguridad.

La aceleración del proceso (una de las variables del valor efectividad) siempre implica riesgo para el resultado cualitativo que se ha de alcanzar. Por lo tanto, incrementar la seguridad puede comprometer la efectividad, y, en contrapartida incrementar la efectividad puede comprometer la seguridad. Basta pensar en las decisiones liminares, inaudita altera parte, para prevención de un daño, en que la seguridad se queda en segundo plano, con vistas a posibilitar la efectividad del probable derecho de la parte.

De tal suerte, el gran desafío del legislador o del aplicador del derecho procesal es componer de manera adecuada esos dos valores en permanente conflicto, y no obstante complementarios. En efecto, los valores se implican reciprocamente, en el sentido de que ninguno de ellos se realiza sin influir, de forma directa o indirecta, en los demás. El mundo de la cultura es siempre un mundo solidario, en el sentido de la interdependencia necesaria de sus factores, pero no en el sentido de la coexistencia pacífica de los intereses, que es un ideal a ser alcanzado. ${ }^{32} \mathrm{El}$ ideal es que la efectividad virtuosa y calificada no venga a causar perjuicio al derecho al proceso justo (a la seguridad, en resumen). Cuando digo eso estoy hablando de adecuación, que en esa perspectiva constituye un concepto básico.

Desde el punto de vista de la lógica jurídica, la adecuación exige una relación empírica entre el medio y el fin, en vista de que el medio debe ser capaz de llevar a la realización del fin. Para que se pueda establecer cuál es el medio adecuado para un determinado fin, es necesario examinar atentamente las especies de relación que existen entre los varios medios disponibles y el fin que se debe promover. Ese análisis puede ser realizado en tres aspectos: cuantitativo (intensidad), cualitativo (cualidad) y de probabilidad (certeza). En términos cuantitativos, un medio puede promover peor, de igual manera, o mejor el fin de que otro fin. Y, en términos de probabilidad, un medio puede promover con menos, igual o más certeza que otro medio. ${ }^{33}$

En el caso del proceso, el fin es el ideal de la justicia material del caso concreto, no siempre alcanzable, como sabemos; el proceso justo y la tutela jurisdiccional efectiva son los medios de que dispone el Estado democrático de derecho, por esencia constitucional, para la realización de aquel fin.

\footnotetext{
27.4.2000, apud Marcus-Helmons, S. Quelques aspects de la notion d'égalité des armes (un aperçu de la jurisprudence de la Cour européenne des droits del'bomme), in Le procès équitable et la protection juridictionnelle du citoyen, Bruxelles, Bruylant, 2001, p. 68.

32 Vid. Reale, M., Filosofia do direito, vol. 1, $5^{\text {a }}$ ed., revisada y aumentada, São Paulo, Saraiva, 1969, n. ${ }^{\circ} 83$, p. 173.

33 Reproduzco las ponderaciones realizadas por Ávila, H., Teoria dos Princípios: da definição à aplicação dos princípios jurídicos, $7^{\mathrm{a}}$ ed., São Paulo, Malheiros, 2007, p. 165, con base en la obra de Ota Weinberger, Rechtslogik, respecto de la adecuación en el examen inherente al postulado normativo que aplica la proporcionalidad.
} 
Frente al carácter normativo de los derechos fundamentales de la efectividad y de la seguridad, pienso que en el ámbito del proceso es posible definir la adecuación de la tutela jurisdiccional como la aptitud de ésta para realizar la eficacia ofrecida por el derecho material, con la mayor efectividad y seguridad posibles. Por lo tanto, la adecuación resulta de la ponderación de esos dos valores o derechos fundamentales, con vistas al resultado que se quiere obtener frente a la clase de derecho violado. Esas directivas deben comprometer al legislador, a la doctrina, y la aplicación práctica del derecho procesal por el órgano judicial, respetados, por supuesto, los dispositivos asegurados para la parte, pues ésta puede elegir la forma de tutela que más le conviene (autonomía de voluntad, otro derecho fundamental), salvo las excepciones consignadas expresamente en la ley.

Ha de reconocerse, sin embargo, que normalmente el conflicto entre los derechos fundamentales de la efectividad y de la seguridad está resuelto previamente por el texto legislativo, presumiblemente en consonancia con el sistema constitucional en que se incluye. La desobediencia al texto sólo será posible cuando su aplicación conduzca a una flagrante injusticia o en vista de un conflicto con otro derecho fundamental, que merezca ser considerado en función de las características especiales del caso concreto. En la aplicación de los derechos fundamentales, solo en casos excepcionales podrá el juez, con el auxilio de postulados hermenéuticos - por ejemplo, la proporcionalidad, la razonabilidad, y la igualdad-, crear una norma que viole de manera flagrante el texto legal.

No obstante, algunas precauciones deben ser tomadas en consideración, so pena de ser transgredido el derecho fundamental a la seguridad, cuya esencia es la previsibilidad.

Estamos aquí en el ámbito de la interpretación y creación del derecho, en el plan jurisdiccional, materia que viene siendo motivo de acentuada atención por parte de la filosofía del derecho actual. En este campo se fortalece cada vez más el entendimiento de que el intérprete, el aplicador del derecho -entre ellos el juez-, el llamado intérprete auténtico (Kelsen), interpreta no normas, sino textos normativos y representaciones fácticas. El producto de la interpretación es la norma; en el caso del juez: la norma de decisión. ${ }^{34}$

Acentúase todavía que además del intérprete auténtico, también los demás integrantes del mundo producen normas, a partir de elementos tomados del texto normativo (mundo del deber ser) y de elementos del caso al cual será aplicado, a partir de datos de la realidad (mundo del ser). Y con base en esa interpretación aplican la norma producida fuera del proceso, aunque no produzcan normas de decisión, tarea exclusiva del órgano judicial. ${ }^{35}$

En ese contexto, la interpretación (= aplicación) del derecho "tiene carácter constitutivo -no meramente declaratorio- y consiste en la producción, por el intérprete, a partir de los textos normativos y de los hechos pertenecientes a un determinado caso, de normas jurídicas que serán ponderadas hacia la solución de este caso, mediante la

${ }^{34}$ Imposible profundizar el examen del tema en esta sede. Ver al respecto Grau, E. R., Ensaio e discurso sobre a Interpretação/Aplicação do direito, $3^{\mathrm{a}}$ ed., São Paulo, Malheiros, 2005, passim, con amplia indicación bibliográfica.

${ }^{35}$ Vid. Grau, E. R. Ensaio, cit., p. 85 
definición de una norma de decisión. Interpretar es, así, dar concreción (= concretizar) al derecho. En ese sentido, la interpretación (= interpretación/aplicación) opera la inserción del derecho en la realidad, opera la mediación entre el carácter general del texto normativo y su aplicación particular, en otros términos: opera su inserción en la vida”. ${ }^{36}$

Sin embargo, la transformación del texto en norma, y con mucho más razón, el alejamiento respecto de la regla, no pueden ser realizados de forma arbitraria por el órgano judicial.

En primer lugar, la actividad del juez es controlada por la red de derechos fundamentales procesales que componen el "proceso justo" (v.g. contradictorio, deber de motivación, juez natural, igualdad, etc.). En segundo lugar, la aplicación debe encontrar acomodo dentro del discurso jurídico, proferido éste con el lenguaje que le es propio. No se olvide que la aprehensión hermenéutica de la realidad, incluso la jurídica, sólo es posible porque el sujeto perceptible conoce de antemano el lenguaje en juego y el alcance de la instrumentación en ella empleada. ${ }^{37} \mathrm{Y}$ el discurso jurídico sólo obliga hasta donde conduzca su fuerza de intrínseca persuasión, fuerza vinculante que ha de ampararse en el sistema jurídico (constitucional e infraconstitucional), en los valores y principios de él originados, y en los valores sociales y culturales dominantes en el seno de la colectividad; en fin en el derecho como totalidad, para que todo no redunde al final en puro arbitrio. ${ }^{38}$

En la colisión entre derechos fundamentales, es necesario ponderar cuál de los intereses en conflicto, en abstracto de la misma categoría, posee mayor peso en el caso concreto. Teniéndose en cuenta las circunstancias específicas de la hipótesis, es posible establecer entre los principios una relación de precedencia condicionada, con precisa indicación de las condiciones en que un precepto debe preceder al otro. Puede ocurrir, por eso, que, en otras condiciones, la precedencia se invierta. ${ }^{39}$

La eventual superación del conflicto entre regla y principio debe ser llevada a cabo con prudencia, so pena de violación del derecho fundamental a la seguridad jurídica, esencial al Estado democrático de derecho.

La regla exhibe una "eficacia de trinchera", que solo puede ser superada por razones extraordinarias y mediante una carga más grande y una fundamentación mejor

36 Vid. Grau, E. R., Ensaio, cit., p. XIII, que refiere, en ese paso, la exposición de Gadamer sobre el pensamiento de Aristóteles.

${ }^{37}$ Vid. Gadamer, H. G., Waherheit und Methode, $4^{\mathrm{a}}$ ed. (1975), pp. 250 y ss., apud A. Menezes Cordeiro, introducción al libro de Claus-Wilhem Canaris, Pensamento sistemático e conceito de sistema na ciência do direito, trad. A. Menezes Cordeiro, Lisboa, Gulbenkian, 1989, p. LIV.

${ }^{38}$ Ver al respecto el excelente prefacio del traductor portugués, J. Baptista Machado, a la obra de Karl Engisch, Introdução ao Pensamento Jurídico, $2^{a}$ ed., Lisboa, Gulbenkian, 1968, cuando trata del descubrimiento del derecho praeter legem e contra legem, esp. p. LVII y LVIII.

${ }^{39}$ Vid. Alexy, R., Teoría de los derechos fundamentales, cit., pp. 90-95, mencionando el interesante ejemplo de conflicto en la hipótesis de realización de una audiencia en que el reo en el proceso penal estaría impedido de comparecer por estar en riesgo de sufrir un infarto del corazón. 
desarrollada, con consideración de los siguientes requisitos: a) justificación adecuada; b) fundamentación adecuada; c) comprobación adecuada. ${ }^{40}$

Sólo con esas precauciones podrá realizarse la justicia del caso. No es posible endosar decisiones escasamente fundamentadas o fundamentadas de manera incorrecta, o aun con falsas motivaciones que, a pretexto de hacer justicia, no acaten derechos fundamentales del ciudadano.

Para concluir, quiero destacar que el aspecto ahora enfocado es de la mayor importancia en el Estado democrático de derecho, tributario del buen uso que hace el juez de sus poderes, cada vez más incrementado por el fenómeno de la incertidumbre y complejidad de la sociedad actual y de la inflación legislativa, con aumento de las reglas de equidad y aplicación de los principios. Justamente, la lealtad en el empleo de esa nueva libertad atribuida al órgano judicial es lo que puede probar la confianza atribuida al juez en la construcción del derecho justo. ${ }^{41}$

Y la seguridad constituye elemento esencial hacia la legitimación del Poder Judicial delante de la sociedad civil.

\section{BIBLIOGRAFÍA}

Alexy, R., Teoría general de los derechos fundamentales, trad. Ernesto Garzón Valdés, Madrid, Centro de Estudios Constitucionales, 1997.

Alexy, R., Direito Constitucional e Direito Ordinário. Justiça Constitucional e Justiça Especializada, trad. Luís Afonso Heck, Revista dos Tribunais, 799, maio/2002.

Alvaro de Oliveira, C. A., Del formalismo en el processo civil (Propuesta de un formalismo valorativo), trad. Prof. Juan José Monroy Palácios, $3^{\mathrm{a}}$ ed., Lima, Palestra Editores, 2007.

Ávila, H., Teoria dos Princípios: da definição à aplicação dos princípios jurídicos, $7^{\mathrm{a}}$ ed., São Paulo, Malheiros, 2007.

BAur, F., Der Anspruch auf rechtliches Gebör, in Beiträge zur Gerichtsverfassung und zum Zivilprozessrecht, Tübingen, J. C. B. Mohr (Paul Siebeck), 1983.

Bedaque, J. R., Efetividade do processo e técnica processual: tentativa de compatibilização, São Paulo, Malheiros, 2006.

Boursier, M-E. ,Le principe de loyautè en droit processuel, Paris, Dalloz, 2003, nº 679.

Casetta, E. Diritti pubblici subiettivi, Enciclopedia del diritto, Milano, Giuffrè, 1964, vol. 12.

Chiovenda, G., Della azione nascente dal contratto preliminare, ensaio publicado en 1911 en la Rivista di Diritto Commerciale, compilado en los Saggi di Diritto Processuale Civile, Roma, Foro Italiano, 1930, vol. 1.

Comoglio, L. P., Lezione Sul Processo Civile (en colaboración con Corrado Ferri y Michele Taruffo), $2^{a}$ ed., Bologna, Il Mulino, 1999.

Comporti, M., Diritti reali in generale, Trattato di diritto civile e commerciale (coord. de Cicu, Messineo e Mengoni), vol. 8, t. 1, Milano, Giuffrè, 1980.

Engisch, K., Introdução ao Pensamento Jurídico, $2^{\mathrm{a}}$ ed., Lisboa, Gulbenkian, 1968.

Gomes Canotilho, J. J., Direito Constitucional, 4ª ed., Coimbra, Almedina, 1987.

\footnotetext{
${ }^{40}$ Vid. Humberto Ávila, Teoria dos Princípios, cit. pp. 119-120.

${ }^{41}$ Marie-Emma Boursier, Le principe de louyauté en droit processuel, cit., p. 372-377, passim.
} 
Gadamer, H. G., Waherheit und Methode, $4^{\mathrm{a}}$ ed.1975.

Grau, E. R., Ensaio e discurso sobre a Interpretação/Aplicação do direito, $3^{\mathrm{a}}$ ed., São Paulo, Malheiros, 2005

Hesse, K., Significado de los derechos fundamentales, in Manual de Derecho Constitucional, $2^{\mathrm{a}}$ ed., trad. Antonio López Pina, Madrid, Marcial Pons, 2001.

Jellinek, G., System der subjektiven öffentlichen Rechte, Tübingen, J.C.B Mohr (Paul Siebeck), $2^{\mathrm{a}}$ ed. 1905.

Marcus-Helmons, S., Quelques aspects de la notion d'égalité des armes (un aperçu de la jurisprudence de la Cour européenne des droits del'homme), in Le procès équitable et la protection juridictionnelle du citoyen, Bruxelles, Bruylant, 2001.

Marinoni, L. G., Técnica processual e tutela dos direitos, São Paulo, Revista dos Tribunais, 2004.

Marinoni, L. G., Da ação abstrata uniforme à ação adequada à tutela dos direitos, in Polêmica sobre a ação - A tutela jurisdicional na perspectiva das relações entre direito e processo, orgs. Fábio Cardoso Machado e Guilherme Rizzo Amaral, Porto Alegre, Livraria do Advogado Editora, 2006.

MeIer, I., Auflösung des geschriebenen Rechts durch allgemeine Prinzipiennormen, in Prinzipiennormen und Verfahrensmaximen, en colaboración con Rudolf Ottomann. Zürich, Schulthess Verlag, 1993.

Mitidiero, D., Processo civil e Estado constitucional, Porto Alegre, Livraria do Advogado ed., 2007.

NaKano, T., Das Prozessrechtsverbältnis, Zeitschrift für Zivilprozess, 79,1966.

Proto Pisani, A., Lezioni di diritto processuale civile, $6^{\mathrm{a}}$ ed., Napoli, Jovene, 2006.

Reale, M., Filosofia do direito, vol. 1, $5^{\text {a }}$ ed., revisada y aumentada, São Paulo, Saraiva, 1969.

Reis Novais, J., Contributo para uma teoria do Estado de Direito, Coimbra, 1978, separata del volumen 24 del Suplemento ao Boletim da Faculdade de Direito da Universidade de Coimbra.

Scherer de Mello Aleixo, P., O direito fundamental à tutela jurisdicional efetiva na ordem jurídica brasileira (a caminho de um "devido processo proporcional"), separata de Direitos fundamentais e direito privado - uma perspectiva de direito comparado, Coimbra, Almedina, 2006.

Vieira de Andrade, J. C., Os Directos fundamentais na Constituição portuguesa de 1976, Coimbra, Almedina, 1987. 